\title{
Differences in pre-pregnancy diet quality by occupation among employed women
}

\author{
Ibrahim Zaganjor 1,*, Suzan L Carmichael ${ }^{2}$, A J Agopian ${ }^{3}$, Andrew F Olshan ${ }^{1}$, \\ Tania A Desrosiers ${ }^{1}$ and The National Birth Defects Prevention Study \\ 'Department of Epidemiology, Gillings School of Global Public Health, University of North Carolina at Chapel Hill, \\ Chapel Hill, North Carolina 27599, USA: ${ }^{2}$ Division of Neonatology and Developmental Medicine, Stanford University \\ School of Medicine, Stanford, California 94305, USA: ${ }^{3}$ Department of Epidemiology, Human Genetics and \\ Environmental Sciences, UT Health School of Public Health, 1200 Pressler, Houston, Texas 77030, USA
}

Submitted 16 November 2018: Final revision received 4 September 2019: Accepted 10 September 2019: First published online 26 February 2020

\begin{abstract}
Objective: Maternal risk factors for pregnancy outcomes are known to vary by employment status. We evaluated whether pre-pregnancy diet quality varies by occupation in a population-based sample.

Design: We analysed interview data from 7341 mothers in a national case-control study of pregnancy outcomes. Self-reported job(s) held during the 3 months before pregnancy were classified using Standard Occupational Classification (SOC) codes. Usual diet in the year before conception was assessed with a semi-quantitative FFQ and evaluated using the Diet Quality Index for Pregnancy (DQI-P). Using logistic regression, we calculated adjusted OR and $95 \%$ CI to estimate associations between low diet quality (defined as the lowest quartile of DQI-P scores) and occupation types.

Setting: The National Birth Defects Prevention Study: Arkansas, California, Georgia, Iowa, Massachusetts, North Carolina, New Jersey, New York, Texas, Utah. Participants: Employed mothers of infants born between 1997 and 2011.

Results: No occupation was strongly associated with low diet quality. Moderate but relatively imprecise associations were observed for women employed in management (OR: 1.3; $95 \% \mathrm{CI}: 1.1,1.7$ ); arts, design, entertainment, sports and media (OR: 1.4; $95 \%$ CI: 0.9, 2.1); protective service (OR 1.3; $95 \%$ CI: 0.7, 2.5) and farming, fishing, and forestry occupations (OR: $0.5 ; 95 \% \mathrm{CI}: 0 \cdot 2,1 \cdot 1$ ). Conclusions: Our analyses suggest that women in certain occupations may have lower diet quality in the months before pregnancy. Further research is needed to determine whether certain occupations could benefit from interventions to improve diet quality in the workplace for women of reproductive age.
\end{abstract}

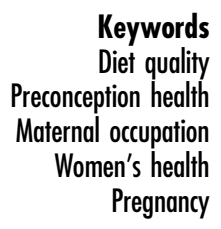

Maternal nutritional status before and during pregnancy is an important determinant of birth outcomes ${ }^{(1-5)}$. Many individual nutrients are critical for fetal growth and development, with the relation between folic acid and neural tube development among the most well-known examples. Since the US initiated fortification of enriched cereal grains with folic acid in 1998, there has been a $35 \%$ decrease in the prevalence of anencephaly and spina bifida and an estimated prevention of 1300 neural tube defect cases annually $^{(6)}$.

Risk of adverse pregnancy and birth outcomes has been shown to vary by occupation ${ }^{(7-10)}$. Many studies have focused on chemical or physical exposures in the workplace potentially related to increased risk of adverse pregnancy outcomes $^{(11-13)}$. Far fewer studies have explored whether these observed associations with occupation may be due to differences in the distribution of maternal behaviours, underlying health conditions or other characteristics that are established risk factors for adverse pregnancy outcomes such as obesity, smoking, socio-economic status and nutritional status.

Currently, there is very limited information about the association between diet quality and occupation, particularly for pregnant women or women of reproductive age ${ }^{(14-16)}$. Identifying occupational groups more likely initiate pregnancy with low diet quality is important given 
the known relation between periconceptional diet quality and adverse reproductive outcomes. The fact that half of pregnancies in the USA are not planned ${ }^{(17)}$ limits opportunities for individual pre-conception counseling, and thus population-level interventions are also needed. Work place health promotion is one such population-level public health strategy which may provide targeted opportunities to improve diet quality for women of reproductive age, especially given that over half of first time mothers are employed during their pregnancy ${ }^{(18,19)}$ and that employed individuals spend substantial proportions of their day at their workplace. Moreover, workplace policies and environmental factors that impact employee diet and nutrition (e.g. cafeteria selection, access to food storage, frequency and duration of breaks for meal times) are prime modifiable targets for intervention ${ }^{(20-22)}$. To further our understanding of the relation between maternal diet quality and occupation, the objective of the current study was to explore whether there are measurable differences in prepregnancy diet quality across specific types of occupations using data from a large population-based study conducted in ten US states between 1997 and 2011.

\section{Methods}

\section{Study sample}

We used data from the National Birth Defects Prevention Study (NBDPS), a case-control study of birth defects ${ }^{(23)}$. Specifically, we used data for women who delivered infants without birth defects (i.e. 'controls' from the parent study). Per NBDPS protocol, approximately 100 mothers per year per state were randomly sampled as controls from birth certificates or hospital delivery records in each of the ten states that contributed to the NBDPS: Arkansas, California, Georgia, Iowa, Massachusetts, North Carolina, New Jersey, New York, Texas and Utah. Eligible women delivered a liveborn infant(s) without a birth defect between 1997 and 2011. Given the population-based sampling framework by which NBDPS controls were selected, this group of women has been shown to be generally representative of their base population with regard to various factors including maternal age, number of previous livebirths, smoking history and diabetes ${ }^{(24)}$.

All women were invited to participate in a computerassisted telephone interview (CATI) in either English or Spanish between 6 weeks and 24 months after the expected date of delivery. During the maternal interview, each woman reported information on a multitude of factors, including maternal age, race/ethnicity, education, pre-pregnancy BMI, pre-pregnancy diabetes, country of birth, folic acidcontaining supplement use, smoking and alcohol consumption before and during pregnancy. Approximately $65 \%$ of eligible women participated in the NBDPS interview.

\section{Classification of occupation}

Occupational histories were collected during the interview. Employed mothers were asked to provide occupational information on jobs they held for at least 1 month during the time period starting 3 months before conception and ending at delivery. Information collected for each job included the name of the company, job title, main duties/activities, month and year the job started/ended, number of days and hours worked per week and what the company made or did. Occupational epidemiologists and industrial hygienists affiliated with the study then used this information to systematically assign a code that best represented the reported occupations based on the 2000 Standard Occupational Classification (SOC) System ${ }^{(25)}$. The SOC system was developed by the United States Bureau of Labor Statistics and is a federal statistical standard used to classify workers into occupational categories based on job characteristics within discrete occupations ${ }^{(25)}$. It utilises a six-digit code with increasing level of occupational specificity at each successive digit to categorise occupations at four different levels: (i) major group; (ii) minor group; (iii) broad occupation and (iv) detailed occupation $^{(25)}$. There are twenty three major occupational groups at the two-digit level (e.g. 250000 ; education, training and library occupations). This process has been previously described in more detail ${ }^{(26)}$.

To account for changes in occupation or employment status that may have been due to pregnancy recognition or other pregnancy-related factors, we restricted our sample to women who were employed during the 3 months preceding conception, from here on referred to as 'pre-pregnancy' or 'before conception'. Each job reported during pre-pregnancy was classified into one of the twenty three major occupational groups based on the corresponding SOC code. If a mother reported having more than one job during this time, a primary job was assigned based on the number of days and hours per week worked at each job. To reduce bias from various sources including the healthy worker effect ${ }^{(27)}$, we excluded women who were not employed, women who reported their exclusive occupation to be student, women who worked at some point during pregnancy but not pre-pregnancy and mothers who were on active military duty.

\section{Assessment of pre-pregnancy diet quality}

To capture pre-pregnancy nutritional information, the maternal interview included a modified Willet $\mathrm{FFQ}^{(28)}$. The original sixty-one item Willet FFQ was modified to better suit the NBDPS study population and research objectives. For example, the FFQ was modified to more fully assess frequency and timing of intake of food items known to have particular relevance to adverse pregnancy outcomes, such as alcohol, sweetened and caffeinated 
beverages and enriched cereals. Another modification was the addition of some food items such as refried beans and avocados to better represent commonly reported foods among the large proportion of Hispanic study participants. This semi-quantitative FFQ captured usual intake of fifty-eight food items in the year before pregnancy; each item was presented with its standard serving size (e.g. whole milk [237 ml glass]), and mothers reported their average intake for each item (range: never or $<1$ per month to 6 or more times per day) ${ }^{(2)}$. We used this information, as well as the detailed information on consumption of cereals and sodas during the 3 months before pregnancy, to estimate usual dietary intake. Usual dietary intakes of specific nutrients were determined using the U.S. Department of Agriculture's nutrient database (version 27) ${ }^{(29)}$. Our analyses utilised the information gathered from the interview to evaluate pre-pregnancy maternal diet in two ways: (i) overall diet quality as measured by the Diet Quality Index for Pregnancy (DQI-P) and (ii) individual DQI-P component scores to explore potential explanations for overall low diet quality.

The DQI-P, modified specifically for the NBDPS, positively scored mothers on six components (grains, vegetables, fruits, folate, iron and calcium) and negatively on two (percentage of calories from fat and sweets) ${ }^{(2)}$. Servings per day as reported on the FFQ were tallied to rank each individual component into quartiles based on the observed distribution within the study sample. Component scores were then summed to obtain the DQI-P score ${ }^{(2)}$, which we also categorised into quartiles. Low diet quality was defined as a DQI-P score in the lowest quartile of scores based on the observed distribution within the study sample.

\section{Analysis}

We first examined the distribution of the twenty three major occupational groups within our study sample and constructed a directed acyclic graph (DAG) to identify factors a priori that may be associated with maternal occupation and pre-pregnancy nutrition (Figure S-1) ${ }^{(30)}$. A minimally sufficient adjustment set was selected after eliminating covariates that had substantial missing data ( $>5 \%$ ) or presented data sparsity issues but did not substantially change the overall association (>10\%). Potential mediators (e.g. household income) were also excluded. Each model adjusted for study center, energy intake (continuous), age at conception (continuous), education ( $<$ high school, = high school, > high school), pre-pregnancy BMI (underweight $[<18.5]$; normal weight [18.5-24.9]; overweight [25.0-29.9]; obese BMI ([ $\left.\left.\geq 30 \cdot 0 \mathrm{~kg} / \mathrm{m}^{2}\right]\right)$ and race/ethnicity (non-Hispanic white, non-Hispanic black, Hispanic, other). Distributions for several excluded covariates or covariates known to be important to the pre-pregnancy period were also examined (i.e. nativity, pre-pregnancy diabetes, folic acid supplement use, smoking and alcohol consumption).

To assess the association between maternal occupation and pre-pregnancy low diet quality, multivariable logistic regression was used to estimate adjusted odds ratios (aORs), 95\% CIs and Bonferroni-adjusted p-values for occupations represented by at least thirty mothers. The reference group for each occupational group was all the other occupational groups combined.

As a supplementary analysis, general linear models (GLMs) were examined to evaluate overall diet quality as a continuous measure (range: 0-24). Regression coefficients and $95 \%$ CIs were estimated to determine differences in mean DQI-P scores between individual occupational groups and the reference group. Similar to the primary analysis, the reference for each occupational group was all other occupational groups combined and estimates were only calculated for groups with at least thirty mothers. All analyses were conducted using complete case analysis methods in SAS version 9.4 (SAS Institute, Inc.).

\section{Results}

A total of 11829 mothers of infants without a birth defect participated in the NBDPS. We excluded 3282 (27.7\%) women who were not employed at any point during pregnancy or the 3 months before; 534 (4.5\%) who were employed at some point during pregnancy but not during the 3 months before conception and 403 (3.4\%) with missing employment information. Of the remaining 7610 women, we excluded $4(0 \cdot 1 \%)$ women with insufficient information to classify occupation and 265 (3.5\%) women missing more than 1 item on the FFQ and/or having an estimated daily energy intake $<2092$ or $>20920 \mathrm{~kJ}$. The final analysis sample consisted of 7341 women.

Mothers most frequency held office and administrative support occupations (19.2\%), sales and related occupations $(11.0 \%)$ and education, training, and library occupations ( $9.7 \%)$ (Table 1$)$. Least commonly held occupations included construction and extraction $(0.3 \%)$, installation, maintenance and repair $(0.2 \%)$ and non-active duty military service $(0 \cdot 1 \%)$. Distributions of maternal characteristics stratified by major occupational group are reported in online supplementary material, Supplemental Tables S-1a and S-1b. A majority of women in each occupational group were Non-Hispanic white with the exception of building and grounds cleaning occupations, farming, fishing and forestry occupations, transportation and material moving occupations and military-specific occupations. Over half of women in each occupational group were born in the USA except for women employed in farming, fishing and forestry occupations (born in the US: $27.7 \%$; $n$ 84). Moreover, BMI values were typically within the normal range (18.5-24.9) among women in most occupational 
Table 1 Association between maternal occupation and pre-pregnancy low diet qualityamong mothers of infants born between 1997 and 2011, National Birth Defects Prevention Study ( $n$ 7341)

\begin{tabular}{|c|c|c|c|c|c|c|c|c|}
\hline \multirow[b]{2}{*}{ Occupational group $\dagger$} & \multirow[b]{2}{*}{$\begin{array}{c}\text { No. } \\
\text { women }\end{array}$} & \multirow[b]{2}{*}{$\%$} & \multicolumn{6}{|c|}{ Diet Quality Index for Pregnancy (DQI-P) } \\
\hline & & & $\begin{array}{l}\text { No. classified } \\
\text { as low diet } \\
\text { quality }\end{array}$ & $\begin{array}{l}\text { No. above } \\
\text { lowest } \\
\text { quartile }\end{array}$ & $\begin{array}{l}\text { Crude } \\
\text { OR }\end{array}$ & $95 \% \mathrm{Cl}$ & $\begin{array}{l}\text { Adjusted } \\
\text { OR } \ddagger\end{array}$ & $95 \% \mathrm{Cl}$ \\
\hline Management & 491 & $6 \cdot 7$ & 189 & 302 & 1.5 & $1 \cdot 2,1 \cdot 8^{\star *}$ & 1.3 & $1 \cdot 1,1 \cdot 7^{*}$ \\
\hline Business and financial operations & 308 & $4 \cdot 2$ & 112 & 196 & 1.3 & $1 \cdot 0,1 \cdot 7^{*}$ & $1 \cdot 1$ & $0.8,1.4$ \\
\hline Computer and mathematical & 117 & 1.6 & 34 & 83 & 0.9 & $0.6,1.4$ & 0.8 & $0.5,1.3$ \\
\hline Architecture and engineering & 34 & 0.5 & 10 & 24 & 0.9 & $0.5,2 \cdot 0$ & 1.0 & $0.4,2.4$ \\
\hline Life, physical and social sciences & 118 & 1.6 & 33 & 85 & 0.9 & $0.6,1.3$ & 1.0 & $0.7,1 \cdot 7$ \\
\hline Community and social service & 180 & 2.5 & 51 & 129 & 0.9 & $0.6,1 \cdot 2$ & 0.8 & $0 \cdot 6,1 \cdot 2$ \\
\hline Legal & 89 & $1 \cdot 2$ & 31 & 58 & $1 \cdot 2$ & $0.8,1.9$ & $1 \cdot 1$ & $0 \cdot 7,1 \cdot 8$ \\
\hline Education, training and library & 710 & 9.7 & 190 & 520 & 0.8 & $0.7,1.0^{*}$ & 0.8 & $0.6,0.9^{*}$ \\
\hline $\begin{array}{l}\text { Arts, design, entertainment, sports } \\
\text { and media }\end{array}$ & 146 & $2 \cdot 0$ & 46 & 100 & $1 \cdot 0$ & $0.7,1.5$ & 1.4 & $0.9,2 \cdot 1$ \\
\hline $\begin{array}{l}\text { Healthcare practitioners and } \\
\text { technical }\end{array}$ & 637 & $8 \cdot 7$ & 179 & 458 & 0.9 & $0 \cdot 7,1 \cdot 1$ & $0 \cdot 8$ & $0 \cdot 6,1 \cdot 0^{*}$ \\
\hline Healthcare support & 339 & 4.6 & 114 & 225 & 1.2 & $0.9,1.5$ & $1 \cdot 1$ & $0.8,1.5$ \\
\hline Protective service & 64 & 0.9 & 22 & 42 & $1 \cdot 2$ & $0.7,2.0$ & $1 \cdot 3$ & $0.7,2.5$ \\
\hline $\begin{array}{l}\text { Food preparation and serving } \\
\text { related }\end{array}$ & 667 & $9 \cdot 1$ & 192 & 475 & $0 . \overline{9}$ & $0 \cdot 8,1 \cdot 1$ & 1.0 & $0.8,1 \cdot 3$ \\
\hline Building and grounds cleaning & 197 & $2 \cdot 7$ & 42 & 155 & 0.6 & $0.4,0.9^{*}$ & $1 \cdot 0$ & $0.6,1.5$ \\
\hline Personal care and service & 441 & $6 \cdot 0$ & 123 & 318 & 0.9 & $0.7,1 \cdot 1$ & 0.8 & $0.6,1.0$ \\
\hline Sales and related & 807 & $11 \cdot 0$ & 244 & 563 & 1.0 & $0.8,1 \cdot 2$ & $1 \cdot 0$ & $0.8,1.2$ \\
\hline Office and administrative support & 1406 & 19.2 & 494 & 912 & $1 \cdot 3$ & $1.1,1.5^{\star \star}$ & $1 \cdot 2$ & $1 \cdot 0,1 \cdot 4^{*}$ \\
\hline Farming, fishing and forestry & 84 & $1 \cdot 1$ & 11 & 73 & 0.3 & $0.2,0 \cdot 6^{\star *}$ & 0.5 & $0 \cdot 2,1 \cdot 1$ \\
\hline Construction and extraction§ & 20 & 0.3 & - & - & - & - & - & - \\
\hline $\begin{array}{l}\text { Installation, maintenance and } \\
\text { repair§ }\end{array}$ & 14 & 0.2 & - & - & - & - & - & - \\
\hline Production & 308 & 4.2 & 81 & 227 & $0 \cdot 8$ & $0.6,1 \cdot 0$ & 0.9 & $0.7,1.3$ \\
\hline Transportation and material moving & 159 & $2 \cdot 2$ & 39 & 120 & 0.7 & $0.5,1 \cdot 1$ & $1 \cdot 1$ & $0.7,1 \cdot 8$ \\
\hline Military specific§ & 5 & 0.1 & - & - & - & - & - & - \\
\hline
\end{tabular}

†The reference group for each occupational group was all the other occupational groups combined.

$\ddagger$ Adjusted for energy intake, study center, maternal age at conception, maternal education, maternal pre-pregnancy BMI and maternal race/ethnicity. $\S$ Rs were not estimated for occupational groups with fewer than thirty women.

${ }^{\star} P$-value $\leq 0.05 ;{ }^{*}$ Bonferroni-adjusted $P$-value $\leq 0.0025$.

groups; however, a high percentage of overweight ( $47.4 \%)$ and obese $(21 \cdot 1 \%)$ women were observed within the small sample ( $n$ 20) of construction and extraction professionals. Notably, the food preparation and serving occupations category was the only group to have a mean age at conception below 25 years (23.4 years). Also, nearly two-thirds of women employed in farming, fishing and forestry occupations had less than a high school education (62.7\%).

\section{Results for Diet Quality Index for Pregnancy}

In general, no occupation(s) were strongly associated with low diet quality. However, a few occupations had slight negative or positive associations with low diet quality. These patterns were observed in both the crude and adjusted analyses, though none of the adjusted estimates remained statistically significant after accounting for multiple comparisons (Table 1). Women employed in arts, design, entertainment, sports and media (aOR: 1.4; $95 \% \mathrm{CI}$ : $0 \cdot 9,2 \cdot 1)$, management (aOR: $1 \cdot 3 ; 95 \% \mathrm{CI}: 1 \cdot 1,1 \cdot 7$ ) and protective service occupations (aOR: 1.3; $95 \%$ CI: 0.7, 2.5) were more likely to have low diet quality when compared to women employed in any other occupational group. In contrast, those employed in farming, fishing and forestry (aOR: $0 \cdot 5 ; 95 \%$ CI: $0 \cdot 2,1 \cdot 1$ ) were less likely to have low diet quality when compared to all other occupations (Table 1). No meaningful differences in results were observed in analyses of DQI-P as a continuous variable (Table S2).

\section{Results for individual diet quality components}

Associations between each of the eight components of the DQI-P and each occupational group were individually assessed to investigate whether specific dietary components might explain any observed associations with overall low diet quality. The majority of aORs for individual components were between 0.8 and 1.4 and relatively imprecise (Table 2). Stronger associations ( $\mathrm{aOR} \leq 0.7$ or $\mathrm{aOR} \geq 1.5$ ) were most commonly detected among protective service (folate, grains and iron), farming, fishing and forestry (calcium, fruits, and percent calories from fat) and architecture and engineering occupations (fruits, iron, percent calories from sweets and percent calories from fat). 
Table 2 Adjusted association between occupational group and low scores on components of the diet quality index among mothers of liveborn infants without a birth defect employed during the pre-pregnancy period, National Birth Defects Prevention Study, 1997-2011 ( $n$ 7341)

\begin{tabular}{|c|c|c|c|c|c|c|c|c|}
\hline \multirow[b]{2}{*}{ Occupational group $†$} & \multicolumn{2}{|c|}{ Calcium (mg) } & \multicolumn{2}{|c|}{$\begin{array}{c}\text { Folate } \\
\text { ( } \mu \text { g dietary folate } \\
\text { equivalents) }\end{array}$} & \multicolumn{2}{|c|}{ Fruits (servings) } & \multicolumn{2}{|c|}{ Grains (servings) } \\
\hline & OR & $95 \% \mathrm{Cl}$ & OR $\ddagger$ & $95 \% \mathrm{Cl}$ & OR & $95 \% \mathrm{Cl}$ & OR & $95 \% \mathrm{Cl}$ \\
\hline Management & 1.0 & $1 \cdot 0,1 \cdot 2$ & $1 \cdot 1$ & $0.9,1.4$ & $1 \cdot 2$ & $1 \cdot 0,1.5$ & $1 \cdot 2$ & $0.9,1.4$ \\
\hline Business and financial operations & $1 \cdot 3$ & $1 \cdot 0,1 \cdot 7$ & $1 \cdot 1$ & $0.8,1.4$ & 1.0 & $0.8,1.3$ & $0 . \overline{8}$ & $0.6,1.0$ \\
\hline Computer and mathematical & 0.7 & $0.4,1.2$ & 0.9 & $0.6,1.5$ & 0.9 & $0.6,1.4$ & 0.6 & $0.4,1.0$ \\
\hline Architecture and engineering & 1.0 & $0.4,2 \cdot 6$ & $1 \cdot 2$ & $0.5,2.8$ & 0.6 & $0.2,1.5$ & 0.9 & $0.4,2 \cdot 0$ \\
\hline Life, physical and social sciences & 0.8 & $0.5,1.4$ & 1.4 & $0.9,2.3$ & 0.8 & $0.5,1.2$ & $1 \cdot 2$ & $0.8,1.9$ \\
\hline Community and social service & $1 \cdot 1$ & $0.7,1.6$ & 0.9 & $0.6,1.3$ & 1.0 & $0.7,1.5$ & 0.8 & $0.6,1.2$ \\
\hline Legal & 0.7 & $0.4,1.2$ & $1 \cdot 3$ & $0.8,2.2$ & 1.5 & $0 \cdot 9,2 \cdot 3$ & $1 \cdot 1$ & $0.6,1 \cdot \overline{7}$ \\
\hline Education, training and library & 0.7 & $0.6,0.9$ & 0.8 & $0.7,1.0$ & 0.8 & $0.6,0.9$ & $1 \cdot 1$ & $0.9,1.3$ \\
\hline Arts, design, entertainment, sports and media & 0.9 & $0.6,1.5$ & 0.9 & $0.6,1.5$ & 0.9 & $0.6,1.4$ & 1.0 & $0.7,1.6$ \\
\hline Healthcare practitioners and technical & 0.8 & $0.7,1.1$ & 0.9 & $0.7,1 \cdot 1$ & 0.9 & $0.7,1 \cdot 1$ & $1 \cdot 0$ & $0.8,1 \cdot 2$ \\
\hline Healthcare support & 1.3 & $1 \cdot 0,1 \cdot 8$ & $1 \cdot 1$ & $0.8,1.5$ & 0.9 & $0.7,1 \cdot 2$ & 0.9 & $0.7,1 \cdot 2$ \\
\hline Protective service & $1 \cdot 0$ & $0.5,1.9$ & 1.9 & $1.0,3.6$ & $1 \cdot 1$ & $0 \cdot 6,2 \cdot 0$ & 1.6 & $0.9,2 \cdot 8$ \\
\hline Food preparation and serving related & 1.0 & $0.8,1.3$ & $1 \cdot 1$ & $0.9,1.4$ & 1.0 & $0.8,1.2$ & $1 \cdot 2$ & $0.9,1.4$ \\
\hline Building and grounds cleaning & 1.5 & $0.9,2.3$ & 0.9 & $0.6,1.5$ & 1.3 & $0.8,1.9$ & 0.9 & $0.6,1 \cdot 3$ \\
\hline Personal care and service & 1.0 & $0.8,1.3$ & 0.8 & $0.6,1.0$ & 0.9 & $0.7,1 \cdot 1$ & 0.9 & $0.7,1 \cdot 2$ \\
\hline Sales and related & 1.0 & $0.8,1.2$ & 0.9 & $0.7,1.1$ & $1 \cdot 2$ & $1 \cdot 0,1.4$ & 1.1 & $0.9,1.2$ \\
\hline Office and administrative support & $1 \cdot 2$ & $1 \cdot 0,1 \cdot 4$ & $1 \cdot 1$ & $0.9,1 \cdot 2$ & 1.2 & $1 \cdot 0,1 \cdot 4$ & $1 \cdot 0$ & $0.9,1 \cdot 1$ \\
\hline Farming, fishing and forestry & 0.3 & $0.1,0.8$ & 0.8 & $0.4,1.6$ & $0 . \overline{6}$ & $0.2,1.3$ & 1.1 & $0.5,2 \cdot 1$ \\
\hline Production & $1 \cdot 1$ & $0.8,1.5$ & 1.0 & $0.7,1.4$ & 0.9 & $0.6,1 \cdot 2$ & 0.9 & $0.6,1 \cdot 2$ \\
\hline \multirow[t]{2}{*}{ Transportation and material moving } & $1 \cdot 1$ & $0 \cdot 7,1 \cdot 7$ & \multicolumn{2}{|c|}{$\begin{array}{c}1.3 \quad 0.8,2.1 \\
\text { Vegetables } \\
\text { (servings) }\end{array}$} & \multicolumn{2}{|c|}{$\begin{array}{l}0.8 \quad 0.5,1.2 \\
\text { Percent calories } \\
\text { from sweets } \$\end{array}$} & 0.9 & $0.6,1.4$ \\
\hline & \multicolumn{2}{|c|}{ Iron (mg) } & \multicolumn{2}{|c|}{$\begin{array}{c}\text { Vegetables } \\
\text { (servings) }\end{array}$} & \multicolumn{2}{|c|}{$\begin{array}{c}\text { Percent calories } \\
\text { from sweets§ }\end{array}$} & \multicolumn{2}{|c|}{$\begin{array}{l}\text { Percent calories } \\
\text { from fat§ }\end{array}$} \\
\hline Occupational group $†$ & OR & $95 \% \mathrm{Cl}$ & OR $\ddagger$ & $95 \% \mathrm{Cl}$ & OR & $95 \% \mathrm{Cl}$ & OR & $95 \% \mathrm{Cl}$ \\
\hline Management & 1.0 & $0.8,1.3$ & $1 \cdot 2$ & $1 \cdot 0,1.5$ & 1.2 & $0.9,1.4$ & 0.8 & $0.6,1 \cdot 1$ \\
\hline Business and financial operations & 0.9 & $0.7,1.3$ & $1 \cdot 2$ & $0.9,1.6$ & 0.9 & $0.7,1 \cdot 2$ & 0.9 & $0.7,1 \cdot 2$ \\
\hline Computer and mathematical & $1 \cdot 1$ & $0.7,1.7$ & 1.4 & $0.9,2.2$ & 1.4 & $1 \cdot 0,2 \cdot 2$ & $1 \cdot 2$ & $0.8,1.8$ \\
\hline Architecture and engineering & 1.5 & $0.7,3.3$ & 0.8 & $0.3,1.9$ & 1.5 & $0.7,3 \cdot 1$ & 0.7 & $0.3,1 \cdot 7$ \\
\hline Life, physical and social sciences & $1 \cdot 1$ & $0.7,1.8$ & $1 \cdot 1$ & $0.7,1.7$ & 1.4 & $0.9,2 \cdot 1$ & 1.0 & $0.6,1.5$ \\
\hline Community and social service & 0.7 & $0 \cdot 5,1 \cdot 1$ & 0.6 & $0.4,0.9$ & 1.0 & $0.7,1.5$ & 1.4 & $1 \cdot 0,2 \cdot 0$ \\
\hline Legal & 1.4 & $0.8,2.3$ & 0.9 & $0.6,1.6$ & 0.9 & $0.6,1.5$ & 0.9 & $0.5,1.5$ \\
\hline Education, training, and library & 1.0 & $0.8,1.2$ & 0.9 & $0.7,1 \cdot 1$ & 1.0 & $0.8,1 \cdot 2$ & 0.9 & $0.7,1 \cdot 1$ \\
\hline Arts, design, entertainment, sports and media & 1.4 & $0.9,2.1$ & 0.8 & $0.5,1.2$ & 1.3 & $0.9,1.9$ & 0.4 & $0.2,0.7$ \\
\hline Healthcare practitioners and technical & 0.9 & $0.8,1.2$ & 0.9 & $0.7,1 \cdot 1$ & 1.0 & $0.9,1.3$ & $1 \cdot 1$ & $0.9,1.3$ \\
\hline Healthcare support & $1 \cdot 2$ & $0.9,1.6$ & 0.9 & $0 \cdot 7,1 \cdot 1$ & 1.2 & $0.9,1.6$ & 0.9 & $0.7,1 \cdot 2$ \\
\hline Protective service & 1.5 & $0.8,2.9$ & 1.4 & $0.8,2.5$ & $1 \cdot 1$ & $0.6,2 \cdot 0$ & 1.3 & $0 \cdot 7,2 \cdot 2$ \\
\hline Food preparation and serving related & 1.0 & $0.8,1.3$ & 1.0 & $0.8,1.3$ & $1 \cdot 0$ & $0.8,1 \cdot 2$ & 1.0 & $0.8,1.3$ \\
\hline Building and grounds cleaning & 0.7 & $0.4,1.2$ & 0.9 & $0 \cdot 6,1 \cdot 1$ & 0.8 & $0.5,1.3$ & 0.8 & $0.5,1 \cdot 1$ \\
\hline Personal care and service & 1.0 & $0 \cdot 7,1 \cdot 2$ & 0.8 & $0 \cdot 6,1 \cdot 1$ & $1 \cdot 1$ & $0.8,1.4$ & 1.0 & $0.8,1.3$ \\
\hline Sales and related & 1.0 & $0.8,1 \cdot 2$ & $1 \cdot 2$ & $1.0,1 \cdot 4$ & 0.9 & $0.7,1 \cdot 1$ & 1.0 & $0.9,1.2$ \\
\hline Office and administrative support & 0.9 & $0.8,1.1$ & $1 \cdot 1$ & $1 \cdot 0,1 \cdot 3$ & 0.9 & $0.8,1.0$ & $1 \cdot 1$ & $0.9,1 \cdot 2$ \\
\hline Farming, fishing and forestry & 1.3 & $0 \cdot 6,2 \cdot 8$ & 0.8 & $0.4,1.6$ & 1.0 & $0.5,2 \cdot 1$ & $2 \cdot 6$ & $1 \cdot 5,4 \cdot 3$ \\
\hline Production & 1.1 & $0.8,1.6$ & 0.8 & $0 \cdot 6,1 \cdot 1$ & 0.8 & $0.5,1 \cdot 1$ & $1 \cdot 2$ & $0.9,1.5$ \\
\hline Transportation and material moving & 1.0 & $0.6,1.7$ & 1.0 & $0.6,1.5$ & $1 \cdot 1$ & $0.7,1 \cdot 7$ & 0.9 & $0.6,1.4$ \\
\hline
\end{tabular}

*Low diet quality is defined as having a Diet Quality Index value in the lowest quartile based on the observed distribution within the study sample.

†The reference group for each occupational group was all the other occupational groups combined.

$\ddagger$ Adjusted for energy intake, study center, maternal age at conception, maternal education, maternal pre-pregnancy BMl and maternal race/ethnicity.

$\S N$ egatively scored components (i.e. a low-quartile value is considered preferable).

\section{Discussion}

The results of our study indicate that pre-pregnancy diet quality may differ across some maternal occupations, though the majority of our results were relatively imprecise with no strong associations. Observed differences in pre-pregnancy diet quality could reflect differences in worksite policies around food storage and meal breaks, occupation-related stressors (physical and psychosocial) and other socio-demographic or lifestyle characteristics.
We found that women employed in farming, fishing and forestry occupations are less likely to have low diet quality; we might hypothesise, for example, that these women may have greater access to fresh fruits and vegetables, thereby scoring higher on the DQI-P.

Though socio-economic factors including education and income are known to be associated with overall diet quality $^{(31,32)}$, there is scant literature on the relation between maternal occupation and diet quality among women of reproductive age. In 2012, Kachan et al. evaluated nutrient 
intake and adherence to dietary guidelines among US workers ( $n$ 8987) using NHANES data ${ }^{(14)}$. The authors reported differences in intake of several nutrients including fibre, calories from saturated fat and calories from carbohydrates among 'blue collar', 'white collar', farming and service occupations, but results were not stratified by age or sex and thus not specific to women of reproductive age. Another study conducted in Japan, which utilised data from a prospective cohort (i.e. the Osaka Maternal and Child Health Study; $n$ 1002), concluded that occupation was not a factor strongly associated with the intake of several assessed nutrients and foods among pregnant women $^{(15)}$, but the current study only compared women who were employed outside of the home to those not employed. Similarly, a study from New Zealand concluded that occupational status did not strongly influence nutrient intake among pregnant women ( $n$ 196) $)^{(16)}$. However, the current study classified women's occupations based on the occupation of each woman's husband/ partner. In the context of such limited research, our study makes a unique contribution to the literature by leveraging a larger population-based sample of employed women in several US states for whom pre-pregnancy occupation could be systematically classified.

Previous research has shown differences in various health outcomes and health-related behaviors by occupation including the Whitehall Study of British civil servants ${ }^{(33)}$. As it pertains to nutrition-related outcomes, results from different studies among employed individuals provide some insight on factors that can partially explain the association between occupation and diet. For example, data from workers in Minneapolis, Minnesota, found that psychological work demands were associated with an increased intake of foods high in fat in men and associated with an increased BMI in women ${ }^{(34)}$. Moreover, participants from a research study in the USA cited several workplace dynamics such as a lack of healthy food options at their worksite, the price of healthy food options, stress-related eating and working through lunch as factors that can negatively influence their worksite eating behaviours ${ }^{(35)}$. These findings point to several structural and psychosocial dynamics that need further research in the context of occupation and diet quality since these are modifiable factors that can be considered in future worksite interventions.

Our analysis has limitations that need to be considered. Our study sample consists of women who successfully conceived and progressed to deliver a liveborn infant; thus, results could be affected by selection bias since infertility and pregnancy loss are also related to pre-pregnancy nutritional status, and the distribution of such outcomes may differ by employment or occupation. Measurement error is also a potential issue because mothers retrospectively reported occupation and usual diet; however, we have no evidence that women in specific occupations would be systematically more or less likely to misreport either their job details or details about their usual food intake. It is also important to note that the timeframes reported for occupation and diet are slightly different (i.e. job details - the 3 months before conception; usual diet - the year before pregnancy). Given that the FFQ in NBDPS was semi-quantitative, we could not evaluate diet quality in reference to recommended dietary allowances (RDA) for specific nutrients. Moreover, while the DQI-P is a validated measure of optimal diet quality for pregnancy, it does lack some specificity; for example, different types of grains (i.e. refined $v$. whole) and fats (i.e. saturated and unsaturated) are weighted equally. As in most epidemiologic studies, there is a potential concern for unmeasured or uncontrolled confounding (e.g. marital status). In the current study, the lack of marital status in the adjustment set may relate to residual confounding by socio-economic status. Despite this concern, the NBDPS is a rich data source with information about many covariates, and we were able to adjust for several important confounders as identified by the DAG including maternal education and race/ethnicity. We also performed sensitivity analyses which demonstrated that there was no additional confounding control when household income was included in the adjustment set. Lastly, we were unable to assess occupations with further granularity due to small sample size constraints. Since we expect some heterogeneity in jobs and job characteristics within each major occupational group, we may have masked some important differences in diet quality within these groups by using such broad occupational classifications in the current analysis.

This analysis has several strengths. First, eligible study participants were randomly selected for a populationbased study of pregnancy outcomes from several states across the US over a period of 14 years. The current study population is demographically diverse and women in the study sample were employed in a wide range of occupations. Mothers of infants without birth defects who participated in the NBDPS were found in a separate analysis to be generally representative of their base populations ${ }^{(24)}$. While the twenty three major occupational groups used in our analysis are broad, the SOC system is a standardised method for classifying occupations in research $^{(36-38)}$ and has the additional benefit of allowing for between-study comparisons. However, a few occupational groups had relatively small sample sizes, which negatively impacted the precision of their estimated odds ratios. We restricted to mothers who worked in the 3 months before pregnancy, thereby minimising potential misclassification due to changes in occupation or employment status due to pregnancy planning or awareness. Further, we reduced errors in assignment to occupational groups among women with multiple jobs by leveraging the detailed self-reported occupational information to determine a primary job. Lastly, our ability to assess 
pre-pregnancy diet quality using an index specific to pregnancy-based recommendations is a major strength of our study. Diet quality indices are informative metrics that represent overall food consumption patterns and often serve as better predictors of health outcomes than measures based on individual nutrients ${ }^{(39,40)}$. Unlike the Healthy Eating Index, which quantifies an individual's overall diet quality based on his or her compliance with the current Dietary Guidelines for Americans ${ }^{(41)}$, the DQI-P was designed specifically for women of reproductive age and includes nutrients critical to optimal pregnancy health (e.g. folate). Despite the advantages of using the DQI-P for our research question, we strongly emphasise that we are not advocating dietary changes based on any specific elements of the index (e.g. we would not recommend lower intake of fat, or higher intake of grains, without further attention to the types of fats or grains). Such recommendations are outside the scope of the current study; rather, our purpose is to describe differences among occupational groups as a first step towards identifying potential avenues for improvement.

Although the relationship between worksite eating habits and overall nutritional status is not well understood, our results emphasise a need to consider women of reproductive age when developing worksite food environment interventions and healthy eating campaigns. Worksite interventions have proven to be effective methods for improving the diets of workers ${ }^{(20)}$ and are particularly valuable since employees with chronic conditions such as obesity have been found to have a greater degree of absenteeism than those with lower BMI values ${ }^{(42,43)}$. Federal agencies and other organisations have developed food service guidelines to help employers provide healthier food and beverage options by operationalising dietary guidance ${ }^{(44,45)}$. It is important to note that these guidelines are designed to help adults meet their daily dietary requirements, and they are not intended for adults with special dietary needs such as pregnant and lactating women. However, employers may be able to use these guidelines as a starting place to help support women of reproductive age better meet their daily nutritional needs.

The findings of this analysis are important because they improve our understanding of the relation between maternal occupation and pre-pregnancy diet quality. The differences in maternal diet by occupation described in this analysis provide valuable information that, taken in context with existing and future research, can be considered by healthcare providers who provide preconception counseling, employers who have the potential to implement positive changes to the workplace such as offering healthy food choices and health behaviour professionals who design workplace wellness programs. Future studies should consider utilising larger study samples in an effort to assess more specific occupational groups and potentially include complementary qualitative research that help elucidate structural barriers and lifestyle factors that may impact the nutritional status and overall health of women of reproductive age in the workforce.

\section{Acknowledgements}

Acknowledgements: The authors thank Kathy Wisniewski for assisting with all secure data transfers and preliminary data management. Moreover, the authors thank Alison Woomert for assisting with all required IRB approvals at the University of North Carolina at Chapel Hill. Financial support: This work was supported by a cooperative agreement from the Centers for Disease Control and Prevention (CDC; U50CCU422096) to the North Carolina Center for Birth Defects Research and Prevention and through COoperative agreements under PA 96043, PA 02081 and FOA DD09-001 from the CDC to other Centers for Birth Defects Research and Prevention participating in the National Birth Defects Prevention Study. This work was also supported in part by the National Institute of Child Health and Development (T32 HD 52468). Conflict of interest: None. Authorship: T.A.D. developed the research question. I.Z. completed the data analysis. All authors contributed to study design, interpretation of the results and writing of the article. Ethics of buman subject participation: The current study was conducted according to the guidelines laid down in the Declaration of Helsinki, and all procedures involving human subjects/patients were approved by Institutional Review Boards at the Centers for Disease Control and Prevention and each of the participating study centers. Verbal informed consent was obtained from all subjects/patients. Verbal consent was observed and formally recorded.

\section{Supplementary material}

To view supplementary material for this article, please visit https://doi.org/10.1017/S1368980019003926

\section{References}

1. Abu-Saad K \& Fraser D (2010) Maternal nutrition and birth outcomes. Epidemiol Rev 32, 5-25.

2. Carmichael SL, Yang W, Feldkamp ML et al. (2012) Reduced risks of neural tube defects and orofacial clefts with higher diet quality. Arch Pediatr Adolesc Med 166, 121-126.

3. Ramakrishnan U, Grant F, Goldenberg Tet al. (2012) Effect of women's nutrition before and during early pregnancy on maternal and infant outcomes: A systematic review. Paediatr Perinat Epidemiol 26, 285-301.

4. Englund-Ögge L, Brantsæter AL, Sengpiel V et al. (2014) Maternal dietary patterns and preterm delivery: Results from large prospective cohort study. BMJ 348, g1446.

5. Thompson JM, Wall C, Becroft DM et al. (2010) Maternal dietary patterns in pregnancy and the association with small-for-gestational-age infants. BrJ Nutr 103, 1665-1673.

6. Williams J, Mai CT, Mulinare J et al. (2015) Updated estimates of neural tube defects prevented by mandatory folic Acid fortification-United States, 1995-2011. MMWR Morb Mortal Wkly Rep 64, 1-5. 
7. Herdt-Losavio ML, Lin S, Chapman BR et al. (2010) Maternal occupation and the risk of birth defects: An overview from the National Birth Defects Prevention Study. Occup Environ Med 67, 58-66.

8. Bell JF, Zimmerman FJ \& Diehr PK (2008) Maternal work and birth outcome disparities. Matern Child Health J 12, 415-426.

9. Farrow A, Shea KM \& Little RE (1998) Birthweight of term infants and maternal occupation in a prospective cohort of pregnant women. The ALSPAC Study Team. Oсcup Environ Med 55, 18-23.

10. Savitz DA, Olshan AF \& Gallagher K (1996) Maternal occupation and pregnancy outcome. Epidemiology 7, 269-274.

11. O'Brien JL, Langlois PH, Lawson CC et al. (2016) Maternal occupational exposure to polycyclic aromatic hydrocarbons and craniosynostosis among offspring in the national birth defects prevention study. Birth Defects Res A Clin Mol Teratol 106, 55-60.

12. Desrosiers TA, Lawson CC, Meyer RE et al. (2012) Maternal occupational exposure to organic solvents during early pregnancy and risks of neural tube defects and orofacial clefts. Occup Environ Med 69, 493-499.

13. Shirangi A, Fritschi L \& Holman C (2008) Maternal occupational exposures and risk of spontaneous abortion in veterinary practice. Occup Environ Med 65, 719-725.

14. Kachan D, Lewis JE, Davila EP et al. (2012) Nutrient intake and adherence to dietary recommendations among US workers. J Occup Environ Med 54, 101-105.

15. Murakami K, Miyake Y, Sasaki S et al. (2009) Education, but not occupation or household income, is positively related to favorable dietary intake patterns in pregnant Japanese women: The Osaka Maternal and Child Health Study. Nutr Res 29, 164-172.

16. Watson PE \& McDonald BW (2009) Major influences on nutrient intake in pregnant New Zealand women. Maternal Child Health J 13, 695.

17. Finer LB \& Zolna MR (2016) Declines in unintended pregnancy in the United States, 2008-2011. N Engl J Med 374, 843-852.

18. U.S. Department of Labor, Bureau of Labor Statistics (2017) Women in the Labor Force: A Databook. https://www. bls.gov/opub/reports/womens-databook/2017/home.htm. (accessed 2018).

19. Laughlin LL (2011) Maternity leave and employment patterns of first-time mothers: 1961-2008. https://www.census.gov/ prod/2011pubs/p70-128.pdf. (accessed June 2018).

20. Mhurchu CN, Aston LM \& Jebb SA (2010) Effects of worksite health promotion interventions on employee diets: A systematic review. BMC Public Health 10, 62

21. Gardner CD, Whitsel LP, Thorndike AN et al. (2014) Foodand-beverage environment and procurement policies for healthier work environments. Nutr Rev 72, 390-410.

22. Almeida FA, Wall SS, You W et al. (2014) The association between worksite physical environment and employee nutrition, and physical activity behavior and weight status. J Occup Environ Med 56, 779

23. Reefhuis J, Gilboa SM, Anderka M et al. (2015) The national birth defects prevention study: A review of the methods. Birth Defects Res A Clin Mol Teratol 103, 656-669.

24. Cogswell ME, Bitsko RH, Anderka M et al. (2009) Control selection and participation in an ongoing, population-based, case-control study of birth defects: The National Birth Defects Prevention Study. Am J Epidemiol 170, 975-985.

25. U.S. Department of Labor Bureau of Labor Statistics (2016) Standard occupational classification, 2000 Standard Occupational Classification (SOC) User Guide. https://www.bls. gov/soc/2000/socguide.htm (accessed June 2018).

26. Lin S, Herdt-Losavio ML, Chapman BR et al. (2013) Maternal occupation and the risk of major birth defects: A follow-up analysis from the National Birth Defects Prevention Study. Int J Hyg Environ Health 216, 317-323.

27. Rocheleau CM, Bertke SJ, Lawson CC et al. (2017) Factors associated with employment status before and during pregnancy: Implications for studies of pregnancy outcomes. $A m J$ Ind Med 60, 329-341.

28. Willett WC, Sampson L, Stampfer MJ et al. (1985). Reproducibility and validity of a semiquantitative food frequency questionnaire. Am J Epidemiol 122, 51-65.

29. U.S. Department of Agriculture, Agricultural Research Service (2016) USDA Nutrient Database for Standard Reference, Release 27. https://www.ars.usda.gov/northeastarea/beltsville-md-bhnrc/beltsville-human-nutrition-researchcenter/nutrient-data-laboratory/docs/sr27-home-page/ (accessed June 2018).

30. Rothman KJ, Greenland S, Lash TL (2008) Modern Epidemiology. Pennsylvania: Lippincott Williams \& Wilkins.

31. Bodnar LM \& Siega-Riz AM (2002) A Diet Quality Index for Pregnancy detects variation in diet and differences by sociodemographic factors. Public Health Nutr 5, 801-809.

32. Rifas-Shiman SL, Rich-Edwards JW, Kleinman KP et al. (2009) Dietary quality during pregnancy varies by maternal characteristics in Project Viva: A US cohort. J Am Diet Assoc 109, 1004-1011.

33. Marmot MG, Stansfeld S, Patel C et al. (1991) Health inequalities among British civil servants: The Whitehall II study. Lancet 337, 1387-1393.

34. Hellerstedt WL \& Jeffery RW (1997) The association of job strain and health behaviours in men and women. Int $J$ Epidemiol 26, 575-583.

35. Devine CM, Nelson JA, Chin N et al. (2007) "Pizza is cheaper than salad": Assessing workers' views for an environmental food intervention. Obesity 15, 57S-68S.

36. Agopian A, Lupo PJ, Herdt-Losavio ML et al. (2012) Differences in folic acid use, prenatal care, smoking, and drinking in early pregnancy by occupation. Prev Med $\mathbf{5 5}$, 341-345.

37. Meyer JD, Nichols GH, Warren N et al. (2008) Maternal occupation and risk for low birth weight delivery: Assessment using state birth registry data. J Occup Environ Med 50, 306-315.

38. Lupo PJ, Langlois PH, Reefhuis J et al. (2012) Maternal occupational exposure to polycyclic aromatic hydrocarbons: Effects on gastroschisis among offspring in the National Birth Defects Prevention Study. Environ Health Perspect 120, 910-915.

39. Kant AK (1996) Indexes of overall diet quality: A review.J Am Diet Assoc 96, 785-791.

40. Kourlaba G \& Panagiotakos DB (2009) Dietary quality indices and human health: A review. Maturitas 62, 1-8.

41. Guenther PM, Casavale KO, Reedy J et al. (2013). Update of the healthy eating index: HEI-2010. J Acad Nutr Diet 113, 569-580.

42. Finkelstein EA, daCosta DiBonaventura M, Burgess SM et al. (2010) The costs of obesity in the workplace. J Occup Environ Med 52, 971-976.

43. Tucker LA \& Friedman GM (1998) Obesity and absenteeism: An epidemiologic study of 10,825 employed adults. Am J Health Promot 12, 202-207.

44. U.S. Centers for Disease Control and Prevention (2018) Healthy Food Environments. https://www.cdc.gov/ obesity/strategies/healthy-food-env.html (accessed June 2018).

45. American Heart Association (2014) Recommended Nutrition Standards for Procurement of Foods and Beverages Offered in the Workplace. https://www.heart.org/idc/groups/heartpublic/@wcm/@adv/documents/downloadable/ucm_320781. pdf (accessed June 2018). 